\title{
A implantação da UTFPR em Apucarana: a qualificação profissional, um investimento no mercado Regional
}

\author{
The deployment of UTFPR in Apucarana: professional \\ qualification, an investment in the Fund
}

\author{
Anderson de Freitas Vietro \\ Eliane da Silva Jatoba \\ Rogério Eduardo Cunha de Oliveira \\ Wierly de Lima Barboza
}

\begin{abstract}
Resumo
Este trabalho objetiva apresentar os benefícios que a Universidade Tecnológica Federal do Paraná trouxe para a cidade de Apucarana e região, ao atender às especificidades profissionais da comunidade, uma vez que o município tem se consolidado, juntamente com outros circunvizinhos, como pólo industrial. As principais questões apontadas se comprovam no histórico do desenvolvimento do mercado industrial da cidade e do consequente empenho das autoridades locais, regionais e até federais pela qualificação profissional através do ensino profissionalizante. É desse anseio por um ensino contextualizado, que atenda às especificidades da sociedade moderna globalizada, que prima pela qualidade, não apenas do saber, mas também, do ser, que levantamos os questionamentos, no final do trabalho, de como a universidade tem correspondido com as constatações apontadas no artigo e quais os subsídios que ela utiliza para tornar-se num referencial.
\end{abstract}

Palavras-chave: universidade, educação profissional, qualificação profissional.

\begin{abstract}
This study presents the benefits that the Federal Technological University of Paraná brought to the city of Apucarana and region, to meet the specific professional community, since the city has been consolidated with other surrounding such an industrial region. The main issues raised are proven in the history of development of the industrial city and the consequent commitment of local, regional and even the federal qualification through vocational education. It is this desire for an education perspective, which allows for the modern, globalized
\end{abstract}


society, who values the quality, not just knowledge but also of being, we raise the questions at the end of work, as the university has responded with the findings outlined in the article and subsidies which it uses to become a reference.

Keywords: University, Professional Education, Vocational Training.

\section{Introdução}

"No início da industrialização capitalista, no século XVIII, o economista Adam Smith recomendava que os trabalhadores tivessem acesso à educação, com a ressalva de que fosse em "doses homeopáticas", oferecendo-se apenas o necessário para se tornarem produtivos e fazer crescer o capital" (ARANHA, 1996:220).

Para a época, a preocupação de Smith era condizente com a realidade social, uma vez que o saber era um bem muito restrito, o qual poucos tinham acesso e condições de possuir. Hoje, porém, no séc. XXI, onde quase não se concebe pensar, por exemplo, em uma indústria que esteja voltada para a transformação de uma determinada matéria-prima em um produto de uso final, já que estamos inseridos num mercado globalizado e que, portanto, utilizam-se os processos de terceirização para fazer funcionar a engrenagem produtiva industrial, a educação, por sua vez, deixou de ser um privilégio de poucos para transformar-se em um requisito indispensável no mundo globalizado do trabalho.

A Educação Profissional foi instituída oficialmente no Brasil a partir do Decreto-Lei no. 7566 de 23 de setembro de 1909, assinado pelo então presidente da república Nilo Peçanha. A criação do ensino profissional estava atrelada ao caráter assistencial do mesmo, e se justifica através do próprio decreto, explicando que se fazia necessária devido ao aumento da população e das "classes proletárias", habilitando "os filhos dos desfavorecidos da fortuna" com preparo técnico e intelectual, ajudando-os a se socializar, sendo essa uma educação "que os afastara da ociosidade ignorante, escola do vicio e do crime". Foram, assim, criadas nas capitais, dezenove Escolas de Aprendizes Artífices vinculadas ao Ministério da Agricultura, Indústria e Comércio custeados pela União e que ofereceriam o ensino profissional gratuito.

Acompanhando este mesmo contexto histórico-social, foi criada a Escola de Aprendizes Artífices do Paraná, em Curitiba, cujas atividades iniciaram-se em 1910 e que, até o ano de 1936, teve como característica fundamental o ensino assistencialista às camadas mais pobres da população e, também, especializado no ensino elementar, oferecendo juntamente os ofícios de alfaiataria, sapataria, marcenaria e serralheria. 
De acordo com o desenvolvimento industrial brasileiro, que se inicia na década de trinta, a Escola de Aprendizes torna-se Liceu Industrial de Curitiba, em 1937, e passa a ofertar o ensino primário. Tais mudanças engajaram-se nas reformas educacionais brasileiras que pretenderam organizar o ensino voltado à industrialização que iniciara no país. E, a partir de 1942, com a Reforma Capanema, sob o nome de Leis Orgânicas do Ensino, estrutura-se o ensino industrial e o ensino comercial, criando, além disso, o Serviço Nacional de Aprendizagem Industrial - SENAI e, juntamente, vieram as mudanças no ensino secundário. Adequando-se ao Decreto-lei n. 4.073, de 30 de janeiro de 1942, que organizou o ensino industrial, o Liceu Industrial de Curitiba transformou-se em Escola Técnica Federal de Curitiba, passando a ofertar o ginásio industrial e os cursos técnicos industriais.

Em 1959 as Escolas Técnicas transformaram-se em Escolas Técnicas Federais e em 1961, através da Lei 4.024 (Lei de Diretrizes e Bases) foi realizada a igualdade plena entre o ensino técnico e o secundário, extinguindo-se a dualidade estrutural. Antevia-se nessas reformas, como pano de fundo, o contexto de políticas desenvolvimentistas pelas quais o país passava, buscando atender, através da expansão e dinamização do ensino profissional, a indústria nacional em ascensão. Porém, somente com a Lei no. 5.692/71, de inspiração tecnicista, ocorreu a profissionalização de todos os cursos secundários. O fim da década de 1960 e início de 1970 coroam a generalização do ensino de 20 grau profissionalizante e buscou-se estender a generalização deste modelo.

De posse de uma autorização especial do Ministério da Educação e Cultura, a Escola Técnica Federal do Paraná passou a ministrar em 1973 o curso superior de Engenharia de Operação, na área de Construção Civil e Elétrica. A partir de 1978 as Escolas Técnicas Federais dos Estados de Minas Gerais, Paraná e Rio de Janeiro, tornaram-se CEFET's (Centro Federal de Educação Tecnológica), o que constitui-Ihes o direito de ofertar o ensino superior.

Durante a década de 90 ocorre a expansão institucional do CEFET Paraná, com a interiorização de suas unidades: Unidade Descentralizada de Medianeira, em 1990; Unidades Descentralizadas de Cornélio Procópio, Pato Branco e Ponta Grossa, em 1993, e a de Campo Mourão em 1995. Concomitante a expansão rumo ao interior, ocorreu a implantação da Lei de Diretrizes e Bases da Educação Nacional (Lei no 9.394, de dezembro de 1996), promovendo a separação entre o ensino técnico e a educação básica e estabeleceu níveis e condições para a educação profissional.

Alain Florent Stempfer , em um artigo na Revista Exame Especial Educação, destaca que o profissional bem remunerado do futuro terá que possuir capacidade de adaptação a novos ambientes e novas situações, mobilidade entre países e culturas e disposição para o aprendizado 
contínuo. Este é o perfil do profissional globalizado, cujas competências são definidas e medidas em termos de performances.

Diante de um quadro tão competitivo, o ensino médio - etapa final de uma educação de caráter geral na perspectiva da nova Lei - "deverá vincular-se ao mundo do trabalho e à prática social" (Art. 1ำ § 20 da Lei 9394/96), através da preparação e orientação básica para a sua integração ao mundo do trabalho, com as competências que garantam seu aprimoramento profissional e permitam acompanhar as mudanças que caracterizam a produção no nosso tempo.

O CEFET-PR torna-se, a partir da Lei no. 11.184, de 07 de outubro de 2005, universidade especializada, passando a denominar-se Universidade Tecnológica Federal do Paraná.

\section{Da Escola Técnica à Universidade}

O Campus Apucarana da UTFPR se estabeleceu nas instalações do antigo Centro Moda, criado a partir de uma iniciativa da diretoria da Associação Comercial, Industrial e de Serviços de Apucarana - ACIA, Gestão 2001, com o apoio do Deputado Federal Alex Canziani, através de um convênio assinado entre o Ministério da Educação - MEC - e a ACIA, com um investimento de mais de R\$ 2,3 milhões, a fundos perdidos, ou seja, sem custo ou contrapartida, com recursos provenientes do Banco Interamericano de Desenvolvimento e do Governo Federal.

No início de suas atividades, o Centro Moda tinha como mantenedora a Fundação de Ensino Técnico de Apucarana - FETAP, e também contou com apoio de diversas entidades: das Prefeituras dos municípios de Apucarana e Marilândia do Sul, do Sindicato das Indústrias do Vestuário de Apucarana e do Vale do Ivaí, da Associação Brasileira dos Fabricantes de Bonés de Qualidade, da Câmara dos Dirigentes Lojistas de Apucarana, da Associação Comercial e Industrial de Apucarana, de quarenta e duas empresas privadas, do SEBRAE, SENAI e SENAC, além de colégios e Faculdades locais.

No ano de 2006, com a expansão da Rede Federal de Educação Tecnológica, dá-se início ao processo de transferência para a gestão do Governo Federal de um grupo de 18 escolas profissionais, até então, administradas por entidades comunitárias (fundações, associações, sindicatos, etc) ou por governos estaduais. Do total das dezoito escolas, doze tiveram o processo de federalização concluído neste mesmo ano e começaram suas atividades como unidades da Rede Federal de Educação Tecnológica, no início do ano letivo de 2007. Dentre estas, o Centro Moda, que passou a ser Campus da Universidade Tecnológica Federal do Paraná - UTFPR, através de um esforço conjunto da ACIA, FETAP, parlamentares junto ao Governo Federal, lideranças políticas da região e Prefeitura Municipal, tendo sua autorização de funcionamento pela Portaria MEC n.o 1.862, de 29/11/06. 
Após autorização do Ministério da Educação, no mesmo ano, realizou-se o exame de seleção para o primeiro curso da UTFPR - Campus Apucarana, o Curso de Educação Profissional Técnica de Nível Médio - Integrado em Industrialização do Vestuário.

Em 12 de fevereiro de 2007, iniciam-se as aulas do Curso Técnico em Industrialização do Vestuário, com duas turmas, uma no período matutino e uma no período vespertino. Também foi realizada a cerimônia de instalação oficial do Campus. O evento contou com a presença do reitor Éden Januário Netto, pró-reitores, diretores dos demais campi, servidores e autoridades. Segundo o Deputado Federal Alex Canziani, presente no evento, a UTFPR tem tradição e qualidade em ensino público, técnico e superior, representando uma grande conquista para Apucarana e região. O parlamentar, que foi um dos articuladores para a instalação do Campus, destaca que aquilo era um sonho que começa a virar realidade: "Trabalhamos bastante neste sentido, mas quem ganha é a comunidade de Apucarana e do Vale do Ivaí".

Tais fatos demonstram as expectativas depositadas sobre a universidade, as quais serão atendidas através do empenho e trabalho de sua equipe, em parceria com a comunidade apucaranense. Dessa forma, sua consolidação e expansão se concretizam com a implantação, no segundo semestre de 2007, do Curso Superior de Tecnologia em Design de Moda e com a criação gradativa de novos cursos, especialmente em nível superior, conforme vem sendo realizado através de projetos de implantação encaminhados ao Conselho .

\section{Compreendendo a viabilidade...}

Apucarana é uma cidade com indústrias de diversos setores. Os de maior destaque são os da indústria têxtil do vestuário e artefatos de tecidos, de produtos alimentícios e bebidas, de moagem de milho e de nutrição animal, de curtidoras de couro e fabricantes de acessórios em couro. Tais setores industriais apresentam características em comum: são setores cujas origens se deram por iniciativas locais, voltados para a pequena produção mercantil rural e urbana (artesanal). São caracterizados pelo uso intensivo de mão-de-obra. São setores dinâmicos, responsáveis pela inserção de Apucarana em redes regionais, nacionais e internacionais de produção e comercialização de diversos produtos. Surgiram e/ou desenvolveram-se em tempos de crise (a partir da década de 1960) em contextos nacional e mundial (VIETRO, 2006, p. 91).

Além desses, outros setores também adquiriram espaço no parque industrial de Apucarana, que conta com indústrias de capital local, de capital nacional e minimamente de capital estrangeiro. Empregam, hoje, mais de 300 funcionários. Há empresas formais, de pequeno e médio porte e, também, informais de confeç̧ões - as chamadas facções. A indústria de transformação de Apucarana é composta por laticínios, abatedouros, frigoríficos, indústrias 
moageiras, fabricantes de bebidas, óleos, alimentos e rações animais, fabricantes de fios, tecidos, acessórios do vestuário, uniformes, malharia, calçados, bolsas e cintos, madeira, mobília, papel, papelão, produtos químicos, fertilizantes, produtos de limpeza, higiene e cosméticos, tintas e vernizes, produtos farmacêuticos, artigos de borracha, plástico, artefatos de concreto, fundição, estruturas metálicas, ferramentas, máquinas e equipamentos, caldeiras, pilhas, baterias e acumuladores elétricos, cabines e carrocerias, equipamentos de transportes, reciclagem de sucatas e produtos diversos (BRASIL, 2007).

Apucarana é conhecida como a Capital Nacional do Boné, título este que adveio da participação da produção local de bonés no total da produção nacional (60 a $70 \%$ atualmente) no início da década de 1990, após sucessivas aberturas de empresas a partir dos anos 1980 e 1990, "conformando um setor especializado na produção de bonés promocionais que futuramente promoveram diversificação da produção, incluindo outros brindes com camisetas, porta CD's, etc." (FRESCA, 2005, p. 5558).

A tabela a seguir exibe as principais atividades em termos de estabelecimentos e pessoal ocupado, para o Paraná, para o município de Apucarana e para os recortes regionais em que o município se insere, com base na Relação Anual de Informações Sociais (RAIS) do Ministério do Trabalho e Emprego (BRASIL, 2007).

Tabela 01 - Principais atividades econômicas em 2007

\begin{tabular}{|c|c|}
\hline \multicolumn{2}{|l|}{ Estado do Paraná } \\
\hline Estabelecimentos & Pessoal ocupado \\
\hline Comércio $40,21 \%$ & Indústria de transformação $24,24 \%$ \\
\hline Agropecuária 11,67\% & Comércio $20,52 \%$ \\
\hline Indústria de transformação $11,47 \%$ & Administração pública $16,77 \%$ \\
\hline $\begin{array}{l}\text { Atividades imobiliárias e de prestação de serviços às empresas } \\
9,82 \%\end{array}$ & $\begin{array}{l}\text { Atividades imobiliárias e de prestação de serviços às empresas } \\
8,4 \%\end{array}$ \\
\hline Transporte, armazenagem e comunicação 5\% & Armazenagem e comunicação 5,22\% \\
\hline \multicolumn{2}{|l|}{ Mesorregião Norte Central Paranaense* } \\
\hline Comércio 39,68\% & Indústria de transformação $29,76 \%$ \\
\hline Indústria de transformação $13,66 \%$ & Comércio $23 \%$ \\
\hline Agropecuária 11,35\% & Administração pública 10,83\% \\
\hline $\begin{array}{l}\text { Atividades imobiliárias e de prestação de serviços às empresas } \\
9,88 \%\end{array}$ & $\begin{array}{l}\text { Atividades imobiliárias e de prestação de serviços às empresas } \\
6,45 \%\end{array}$ \\
\hline Saúde e serviços sociais $4,75 \%$ & Educação 5,05\% \\
\hline \multicolumn{2}{|l|}{ Microrregião de Apucarana** } \\
\hline Comércio 37,23 & Indústria de transformação $47,69 \%$ \\
\hline Industrias de transformação 21,58 & Comércio 19,05\%, \\
\hline Agropecuária 10,67 & Administração pública 9,99\%, \\
\hline Atividades imobiliárias e de prestação de serviço às empresas & Outros serviços coletivos, sociais e pessoais $5,82 \%$ \\
\hline
\end{tabular}




\begin{tabular}{l|l}
\hline 7,03 & \\
Construção 5,27 & $\begin{array}{l}\text { Atividades imobiliárias e de prestação de serviços às empresas } \\
3,6 \%\end{array}$ \\
\hline
\end{tabular}

\section{Município de Apucarana}

\begin{tabular}{|c|c|}
\hline Comércio 35,59\% & Indústria de transformação 47,54\%, \\
\hline Indústria de transformação $25,97 \%$ & Comércio $20,65 \%$, \\
\hline Agropecuária 7,83\% & Administração pública $8,43 \%$, \\
\hline $\begin{array}{l}\text { Atividades imobiliárias e de prestação de serviços às empresas } \\
7,25 \%\end{array}$ & Outros serviços coletivos, sociais e pessoais $6,12 \%$ \\
\hline Saúde e serviços sociais $4,1 \%$ & Transporte, armazenagem e comunicação 3,65\%. \\
\hline
\end{tabular}

Fonte: BRASIL, MTE-RAIS, 2007.

* Composta pelas Microrregiões de Astorga, Porecatu, Floraí, Maringá, Apucarana, Londrina, Faxinal e Ivaiporã.

** Composta pelos Municípios de Apucarana, Arapongas, Califórnia, Cambira, Jandaia do Sul, Marilândia do Sul, Mauá da Serra, Novo Itacolomi, Sabáudia.

Tudo isso faz da atividade industrial a maior empregadora em todos os níveis de análise e apresenta a maior participação na empregabilidade, à medida que diminuem as escalas de análise do estado ao município de Apucarana.

\section{UTFPR de olhos no futuro...}

"[...] é importante indicar que a preparação para o mundo do trabalho requer o desenvolvimento nas novas gerações, não só, nem principalmente de conhecimentos, idéias, habilidades e capacidades formais, mas também da formação de disposições, atitudes, interesses e pautas de comportamento. Estas devem ajustar-se às possibilidades e exigências dos postos de trabalho e sua forma de organização em coletividade ou instituições, empresas, administrações, negócios, serviços..." (SACRISTÁN, 1998:15)

A partir desses indicativos é que a UTFPR pauta-se para traçar o seu perfil de universidade voltada para a realidade local, projetando-se sempre para o futuro: a inovação, a transformação, o aperfeiçoamento, através de pesquisas científicas. Alguns questionamentos são levantados a partir das constatações acima expostas, tais como: se a realidade dos setores prima pela mão-deobra, como é feita a qualificação profissional para suprir a demanda industrial? Quais os investimentos realizados nesta modalidade educacional? Quais os agentes envolvidos que possibilitam o alcance dos objetivos propostos? Quais as perspectivas para o futuro da educação profissional em Apucarana a partir da instalação do Campus da Universidade Tecnológica Federal do Paraná (UTFPR)? Como a UTFPR pode contribui para a superação da necessidade de profissionais com atitudes e disposição para uma organização coletiva? 
O histórico do desenvolvimento do campus Apucarana, desde a sua implantação, respondem positivamente aos questionamentos acima apontados. A universidade tem interagido com o setor produtivo regional de diversas maneiras: pela oferta de cursos de curta duração destinados ao treinamento profissional, realizados nos laboratórios da instituição ou nas dependências das empresas, tanto em nível de chão-de-fábrica , quanto de gestão; pela oferta de cursos especializados, visando à disseminação de novas técnicas produtivas; pela realização de eventos de divulgação científica; pela participação dos pesquisadores em projetos, como o de levantamento dos resíduos sólidos da produção de bonés; através do ingresso dos estagiários nas empresas a partir de 2009.

E suas atividades não se limitam apenas aos âmbitos internos do campus, mas tem prestado uma ativa participação junto a órgãos de influência, como o Arranjo Produtivo Local (APL) de Bonés de Apucarana, nas reuniões do APL de Móveis de Arapongas e do APL de Confeç̧ões de Londrina. Deve-se destacar também, a interação da UTFPR com as demais Instituições de Ensino Superior do município, como a FECEA, em que a UTFPR é parceira num projeto que visa à correta destinação dos resíduos sólidos da indústria de confecção e a geração de renda. Essas ações têm proporcionado ao campus a construção de uma imagem de universidade referência.

Os recursos assegurados junto ao REUNI para a implantação de novos cursos de graduação - Tecnologia de Processos Químicos, Engenharia de Produção Têxtil e Licenciatura em Química - também veio proporcionar grande oportunidade de consolidar a política crescente da UTFPR com outros setores industriais - a integração da cadeia têxtil-confeccionista, a indústria química, alimentícia, moveleira - mediante a oferta de serviços tecnológicos, consultorias, formação de profissionais de nível superior.

O Departamento de Pesquisa e Pós-graduação no final de 2008 abriu as perspectivas para a inserção da Instituição, na verticalização completa do ensino. Oferecendo nas três modalidades - ensino médio, ensino superior e ensino superior tecnológico - pós-graduação, ampliando o quadro de oportunidade aos alunos para ascensão profissional.

Atualmente o campus oferece o Programa Especial de Formação Pedagógica - COFOP, à formação continuada de profissionais, atendendo às demandas de professores para a região. Este curso possibilita aos profissionais portadores de diploma de graduação uma habilitação na docência, em cursos relacionados com a habilitação pretendida, com o mínimo de 160 horas cursadas. As disciplinas pleiteadas podem ser correlatas às áreas de Matemática, Química, Biologia, Física, Espanhol e disciplinas profissionalizantes. O Programa habilita ao exercício de magistério na disciplina requerida dentro do currículo de base nacional comum e que integram as 
quatro últimas séries do ensino fundamental, o ensino médio e a educação profissional em nível médio nos diferentes Sistemas de Ensino.

A expansão das atividades agroindustriais com a implantação de empresas avícolas na região representa oportunidades para a instituição. $O$ desenvolvimento de inovações tecnológicas a torna referência em tecnologia, apresentando-se como um novo desafio institucional: o desafio de implementar inovação tecnológica embasada num referencial acadêmico de primeira linha, superando as expectativas da sociedade moderna globalizada.

É nessa perspectiva de desenvolvimento de um processo sustentável, considerando as perspectivas, os limites e as possibilidades educacionais, tecnológicas e sociais, que temos trabalhado na construção de uma educação com possibilidade histórica, com ações concretas, respeitando a ordem social.

\section{Referências}

ARANHA, Maria Lúcia de Arruda História da Educação, 2ae ed., São Paulo: Moderna, 1996.

BRASIL, Ministério do Trabalho e Emprego. RAIS - Relação Anual de Informações Sociais - 20052007. Brasília, 2007. (cd-rom).

, Secretaria de Comércio Exterior. Relação de exportação e importação: Apucarana, 2007 e 2008. Brasília, 2008.

FRESCA, T. M. A rede urbana norte-paranaense e cidades especializadas em produções industriais: Arapongas, Apucarana e Cianorte. In: Encontro de geógrafos da América Latina, 10., 2005, São Paulo. Anais... São Paulo: Usp, 2005. p.5554-5574.

IPARDES. Cadernos municipais: Apucarana. Curitiba, 2008.

SACRISTÁN, J. Gimeno. Compreender e transformar o ensino. 4aed. ArtMed, 1998.

STEMPFER, Alain Florent. Seu filho tem que ser melhor que você. Brasil em Exame, Edição Especial Educação, setembro/ 1997 p. 36-37.

VIETRO, A. F. O processo de industrialização de Apucarana: a capital nacional do boné. 2006, 93p. Monografia (Bacharelado em Geografia) - Universidade Estadual de Londrina.

Anderson de Freitas Vietro - Técnico em Assuntos Educacionais - UTFPR Campus Apucarana, Cursando Mestrado em Geografia, andersonfreitas@utfpr.edu.br 
Eliane da Silva Jatoba - Técnico de Assuntos Educacionais - UTFPR Campus Apucarana, Cursando Especialização em História, elianejatoba@utfpr.edu.br

Rogério Eduardo Cunha de Oliveira - Técnico de Assuntos Educacionais - UTFPR - Campus

Apucarana, Cursando Especialização em Educação Profissional Integrada à Educação Básica, na modalidade EJA - rogeriooliveira@utfpr.edu.br

Wierly de Lima Barboza - Pedagoga - UTFPR - Campus Apucarana - Especialista em Avaliação Escolar e Psicopedagogia - wierly@utfpr.edu.br 